\title{
Pathogenesis of Irritable Bowel Syndrome: Is It Really in the Gene?
}

\author{
Uday C Ghoshal* and Rajan Singh \\ Department of Gastroenterology, Sanjay Gandhi Postgraduate Institute of Medical Sciences, Lucknow, India
}

\author{
Article: Association between $S L C 6 A 4$ serotonin transfer gene linked polymorphic region and $A D R A 2 A-1291 C>G$ and \\ irritable blowel syndrome in Korea \\ Choi YJ, Hwang SW, Kim N, Park JH, Oh JC, Lee DH. \\ (J Neurogastroenterol Motil 2014;20:388-399)
}

Irritable bowel syndrome (IBS) is a common gastrointestinal (GI) disorder in the community and clinical practice. The prevalence of IBS in Asian communities varies from $2.9 \%$ to $15.6 \%{ }^{1}$ The pathogenesis of IBS is largely unknown. However, abnormal gut motility, dysbiosis, food intolerance such as lactose intolerance, visceral hypersensitivity, low-grade inflammation and abnormal brain-gut interaction have been incriminated in its pathogenesis. ${ }^{2}$ High degree of concordance among monozygotic twin and familial aggregation suggested a role of genetic factor in pathogenesis of IBS. ${ }^{3}$ Though some experts suggested that familial aggregation might be explained by learned behavior, ${ }^{4}$ contribution of genetic factors is being explored in multiple studies in the recent literatures.

How do the genetic factors influence occurrence of IBS? IBS is a multi-factorial polygenic disorder. Since gut motility, visceral sensation, degree of inflammation in response to microbes in the gut, food intolerance such as lactose intolerance and brain-gut in- teraction are all mediated by neuro-peptides, hormones and cytokines and various other proteins, which are transcribed from different genes, alteration in these genes may lead to alteration in these physiological processes. ${ }^{5}$ Several studies found association between polymorphisms in various genes such as serotonin transporter (SERT or SLC6A4), $\alpha_{2}$ adrenergic receptor, cytokine and G-protein genes and IBS. ${ }^{6-9}$

Genetic variations in $\alpha_{2}$ adrenergic receptor may influence visceral sensation in patients with IBS. The $\alpha_{2 \mathrm{c}}$ Del 322-325 and $\alpha_{2 \mathrm{c}}-1291 \mathrm{C}>\mathrm{G}$ polymorphisms result in reduced pre-synaptic $\alpha_{2}$ adrenoceptor function, and norepinephrine released from the pre-synaptic nerve endings is not effectively inactivated by re-uptake and subsequent monoamine oxidation. ${ }^{10}$ Increased synaptic norepinephrine may inhibit cholinergic enteric motor neurones, reducing GI motility. In a study from USA, $\alpha_{2 c}$ Del 322-325 deletion polymorphism, which results in loss of four amino acids (Gly-Ala-Gly-Pro) at positions 322-325, was found associated

Received: June 3, 2014 Revised: June 11, 2014 Accepted: June 11, 2014

(c) This is an Open Access article distributed under the terms of the Creative Commons Attribution Non-Commercial License (http://creativecommons. org/licenses/by-nc/3.0) which permits unrestricted non-commercial use, distribution, and reproduction in any medium, provided the original work is properly cited.

*Correspondence: Uday C Ghoshal, MD, DNB, DM, FACG, RFF

Department of Gastroenterology, Sanjay Gandhi Postgraduate Institute of Medical Sciences, Lucknow 226014, India

Tel: +91-522-2668017, Fax: +91-522-2668078, E-mail: udayghoshal@gmail.com

Financial support: None.

Conflicts of interest: None.

Author contributions: Uday C Ghoshal and Rajan Singh contributed equally in conceptualizing, writing the manuscript and reviewing the literature. ORCID: Uday C Ghoshal, http://orcid.org/0000-0003-0221-8495. 
with constipation predominant IBS (IBS-C). ${ }^{10}$ In another study from India, $\alpha_{2 a}-1291 C>G$ was associated with diarrhea predominant IBS (IBS-D), but not with IBS-C. ${ }^{7}$ A common polymorphism in Catechol-O-methyltransferase, which is known to cause valine substitution to methionine causing altered enzyme activity, was found to be associated with IBS. ${ }^{11}$ Cannabinoid receptors modulate a variety of GI functions, including pain modulation, inflammation, and gastric and colonic motility. ${ }^{12}$ The gene that codes for cannabinoid receptor 1 (CNR1) contains a polymorphic (AAT)n triplet repeat in the 3-flanking region of the CNR1 gene. Expression of this gene is inversely proportional to the number of AAT repeats. ${ }^{13}$ In a study from Korea, this polymorphic (AAT)n triplet repeat of the (CNR1) gene is related to IBS and severity of abdominal pain among them. ${ }^{12}$

Low-grade inflammation has been implicated in the pathophysiology of IBS. In a meta-analysis on 5 studies that investigated IL-10 (an anti-inflammatory cytokine) 1082G/A, TGF$\beta 1$ (anti-inflammatory) $+869 \mathrm{~T} / \mathrm{C}$ and $+915 \mathrm{G} / \mathrm{C}$ and $\mathrm{TNF}$ (pro-inflammatory) 308G/A polymorphisms in patients with IBS and controls were included. High producer of anti-inflammatory cytokine IL-10 (1082) was associated with a reduced risk of IBS. ${ }^{8}$ Though no association was found between TNF (308G/A) genotypes and IBS, in sub-group analysis of the Asian studies, there was an association between TNF (308 G/A and G/G) genotypes and IBS. ${ }^{8}$ A study from our centre on IL-1 receptor antagonist (IL-1RA) polymorphism showed that genotype 1/1 (over-producer of IL1-RA) was infrequent among patients than controls. ${ }^{14}$

Cholecystokinin (CCK) is released by endocrine cells within the duodenal and jejunal mucosa in response to products of protein and fat digestion. Therapeutic blockade of CCK1 receptors (CCK1R) may stimulate gut motility and may reduce colonic transit time in patients with IBS-C. ${ }^{15}$ A polymorphism in CCK1R gene $(779 \mathrm{~T}>\mathrm{C})$ was found to be associated with slower gastric emptying among patients with IBS-C. ${ }^{16}$ This suggests that, compared with the 779T variant, the $779 \mathrm{C}$ substitution results in an increased response to endogenous $\mathrm{CCK}$, prolonging gastric emptying.

Serotonin or 5-hydroxytryptamine (5-HT) is an important molecule for stimulating GI motility, secretion and enhancing visceral sensation. Serotonergic neurotransmission is regulated by SERT, which transports the serotonin released into the synaptic cleft back to the pre-synaptic nerve endings. Polymorphisms in SERT gene, encoding the transporter protein, affect transcriptional activity and influence 5-HT re-uptake efficiency. The
5-HT transporter-linked polymorphic region (5-HTTLPR) comprises a repetitive sequence with an insertion-deletion variation. ${ }^{6}$ In a meta-analysis on 25 studies including $3,443 \mathrm{pa}-$ tients with IBS and 3,359 controls, L/L genotype was demonstrated to be a risk factor for the development of IBS-C. In the analysis of different ethnicities, $\mathrm{L}$ allele and $\mathrm{L} / \mathrm{L}$ genotype were significantly associated with increased IBS-C risk in the East Asian population, but not in the Caucasian population. ${ }^{17}$ In a study from our center on SLC6A4 polymorphism of SERT showed that deletion/deletion genotype of SLC6A4 polymorphism was associated with IBS, particularly IBS-D. ${ }^{6}$

G-protein beta-3 subunit gene (GN $\beta 3$ ), C825T polymorphism alters intra-cellular signal transduction, which may lead to motor or sensory abnormalities of the GI tract. ${ }^{18}$ One study aimed to show association between GN $\beta 3$ C $825 \mathrm{~T}$ among Korean children with IBS. They showed that $\mathrm{C} / \mathrm{C}$ genotype of GN $\beta 3$ C825 T was more common in patients with IBS than controls. Also, C/C genotype was common in IBS-D, and the T/T genotype was common in IBS-C. ${ }^{19}$ However, a meta-analysis on seven case-control studies including 1,085 patients with IBS and 1,695 healthy controls did not show any association between GN $\beta 3$ C825T polymorphism and IBS. ${ }^{9}$

The current issue of the journal presented a study on $99 \mathrm{pa}-$ tients with IBS and 171 healthy controls evaluating a possible association between SLC6A4 5-HTTLPR, ADRA2A 1291C > $\mathrm{G}$, GNB3 $825 \mathrm{C}>\mathrm{T}$, CCK1R intron 779T $>\mathrm{C}$, and TRPV1 $945 \mathrm{G}>\mathrm{C}$ polymorphisms and $\mathrm{IBS} .^{20}$ The authors showed that L/L genotype of 5-HTTLPR polymorphism was significantly associated with the total IBS, IBS-C and mixed IBS (adjusted OR: $4.35,95 \%$ CI: 1.04-16.67; adjusted OR: $11.11,95 \%$ CI: 1.69-50.00 and adjusted OR: 5.56, 95\% CI: $1.05-33.33$, respectively). ADRA2A $1291 \mathrm{G}$ allele was significantly associated with total IBS and IBS-D (adjusted OR: 3.37, 95\% CI: 1.16-9.77 and adjusted OR: 5.64, 95\% CI: 1.18-27.01). However, GNB3 $825 \mathrm{C}>\mathrm{T}$, CCK1R intron $779 \mathrm{~T}>\mathrm{C}$ and TRPV1 $945 \mathrm{G}>\mathrm{C}$ polymorphism did not show significant differences between patients and controls. Also, patients with IBS-C showed reduced level of serum serotonin compared to controls and IBS-D patients $(50.2 \mathrm{ng} / \mathrm{mL}$ vs. $69.0 \mathrm{ng} / \mathrm{mL}$ and 92.9 $\mathrm{ng} / \mathrm{mL}, P=0.017$ and $P=0.001$, respectively).

Though this is an important step towards attempting to understand genetic basis of IBS, it suffers from limitation due to inadequate power resulting from relatively small sample size. Moreover, since the authors studied several genetic polymorphism, multivariate analysis would have helped us to under- 
stand interplay between various genetic factors and independent effect of each gene. Moreover, since IBS is a multi-factorial polygenic disorder, relative effect of environmental factors in addition to genetic factors would have thrown more light into pathogenesis of IBS. Though measurement of serotonin level has given an important insight into the pathogenesis, therapeutic manipulation of which is expected to help managing these patients, estimation of the serum sample rather than tissue is a limitation of this study. However, in spite of these limitations, the present study is an important step towards understanding the genetic basis of IBS; it reminds us the famous saying by Robert Fulghum, an American author, "I believe that imagination is stronger than knowledge. That myth is more potent than history. That dreams are more powerful than facts $\cdots . "$

\section{References}

1. Gwee KA, Bak YT, Ghoshal UC, et al. Asian consensus on irritable bowel syndrome. J Gastroenterol Hepatol 2010;25:1189-1205.

2. Lee YJ, Park KS. Irritable bowel syndrome: emerging paradigm in pathophysiology. World J Gastroenterol 2014;20:2456-2469.

3. Locke GR 3rd, Zinsmeister AR, Talley NJ, Fett SL, Melton LJ 3rd. Familial association in adults with functional gastrointestinal disorders. Mayo Clin Proc 2000;75:907-912.

4. Talley NJ. Irritable bowel syndrome and health care seeking: do we pass our bad habits onto our children? Am J Gastroenterol 2000; 95:340-341.

5. Fukudo S, Kanazawa M. Gene, environment, and brain-gut interactions in irritable bowel syndrome. J Gastroenterol Hepatol 2011;26(suppl 3):110-115.

6. Kumar S, Ranjan P, Mittal B, et al. Serotonin transporter gene (SLC6A4) polymorphism in patients with irritable bowel syndrome and healthy controls. J Gastrointestin Liver Dis 2012;21:31-38.

7. Sikander A, Rana SV, Sharma SK, et al. Association of alpha 2A adrenergic receptor gene (ADRAlpha2A) polymorphism with irritable bowel syndrome, microscopic and ulcerative colitis. Clin Chim Acta 2010;411:59-63.

8. Bashashati M, Rezaei N, Bashashati H, et al. Cytokine gene polymorphisms are associated with irritable bowel syndrome: a systematic review and meta-analysis. Neurogastroenterol Motil 2012;24:1102e566.
9. Pan ZG, Xiao C, Su DX. No association of G-protein beta polypeptide 3 polymorphism with irritable bowel syndrome: evidence from a meta-analysis. World J Gastroenterol 2014;20:6345-6352.

10. Kim HJ, Camilleri M, Carlson PJ, et al. Association of distinct $\alpha_{2}$ adrenoceptor and serotonin transporter polymorphisms with constipation and somatic symptoms in functional gastrointestinal disorders. Gut 2004;53:829-837.

11. Karling P, Danielsson $\AA$, Wikgren M, et al. The relationship between the val158met catechol-O-methyltransferase (COMT) polymorphism and irritable bowel syndrome. PLoS One 2011;6:e18035.

12. Park JM, Choi MG, Cho YK, et al. Cannabinoid receptor 1 gene polymorphism and irritable bowel syndrome in the Korean population: a hypothesis-generating study. J Clin Gastroenterol 2011; 45:45-49.

13. Jiang Y, Nie Y, Li Y, Zhang L. Association of cannabinoid type 1 receptor and fatty acid amide hydrolase genetic polymorphisms in Chinese patients with irritable bowel syndrome. J Gastroenterol Hepatol 2014;29:1186-1191.

14. Ghoshal UC, Srivastava D, Ghoshal U, Mittal RD. Genetic variants producing less IL-1RA are commoner in irritable bowel syndrome than controls and patients with small intestinal bacterial overgrowth have higher intestinal mucosal IL- $1 \alpha$ and $\beta$ levels than those without: evidence for gut inflammation. Gastroenterology 2014;146 (suppl 1):S-534

15. D'Amato M, Rovati LC. Cholecystokinin-A receptor antagonists: therapies for gastrointestinal disorders. Expert Opin Investig Drugs 1997;6:819-836.

16. Park SY, Rew JS, Lee SM, et al. Association of CCK1 receptor gene polymorphisms and irritable bowel syndrome in Korean. J Neurogastroenterol Motil 2010;16:71-76.

17. Zhang ZF, Duan ZJ, Wang LX, Yang D, Zhao G, Zhang L. The serotonin transporter gene polymorphism (5-HTTLPR) and irritable bowel syndrome: a meta-analysis of 25 studies. BMC Gastroenterol 2014;14:23.

18. Park MI. Is there enough evidence for the association of GN $\beta 3$ C825T polymorphism with functional dyspepsia and irritable bowel syndrome? J Neurogastroenterol Motil 2012;18:348-349.

19. Park CS, Uhm JH. Polymorphisms of the serotonin transporter gene and G-protein $\beta 3$ subunit gene in Korean children with irritable bowel syndrome and functional dyspepsia. Gut Liver 2012;6:223-228.

20. Choi YJ, Hwang SW, Kim N, Park JH, Oh JC, Lee DH. Association between $S L C 6 A 4$ serotonin transfer gene linked polymorphic region and $A D R A 2 A-1291 \mathrm{C}>\mathrm{G}$ and irritable blowel syndrome in Korea. J Neurogastroenterol Motil 2014;20:388-399. 